\title{
The NFL Salary Cap and Veteran Players' Salaries
}

\author{
K. H. McIntyre \\ Department of Economics \& Business Administration \\ McDaniel College, Westminster, MD, USA
}

\begin{abstract}
The salary structure and process of wage determination in the American National Football League (NFL) is perhaps unique among professional sports: contracts are not guaranteed, careers tend to be very short, and the league operates under a salary cap that limits teams' payrolls. Thus, while a fairly well-defined set of performance metrics exists for most professional football players, the usual relationship between measured performance and compensation-i.e. higher productivity translates into higher pay may be blurred, empirically observable, or even nonexistent. This paper investigates this issue using a four-year panel of veteran professional football players. Our analysis suggests that although performance plays a role in determining salaries in the NFL, experience, durability, and mobility are the most important factors veteran player compensation.
\end{abstract}

Keywords: National Football League (NFL), professional athletics, wage determination, salary cap.

\section{INTRODUCTION}

Anyone who has ever listened to sports talk radio knows that the pay scale for professional athletes is one of the favorite topics of discussion among sports fans and members of the media, especially around draft days, free agency periods, and trade deadlines. This should not be surprising: the business of sports has never been bigger or more closely scrutinized, and athletics and sundry merchandising more aggressively marketed; professional athletes' salaries are simply part of this trend. This coupled with a similar zenith regarding the degree of labor mobility in the four major North American professional team sports makes professional athletics a fertile area for timely, interesting, and accessible research in wage and salary determination, as well as an opportunity to revisit and update some classic empirical methods used by labor economists.

The issue of professional athletes' compensation is one that academics have been concerned with for some time now. The basic notion is that professional athletes' performance statistics represent-more so than in most other occupations-an essentially pure measure of a worker's productivity and market attributes. This line of research is now in its fourth decade, dating to the initial work by Gwartney and Haworth [1] on discrimination in the market for professional baseball players. The intervening years have witnessed a noteworthy expansion the literature dealing with Major League Baseball's labor market (Medoff [2], McDonald and Reynolds [3], Irani [4], Hanssen [5]), in addition to forays into American professional basketball (Kahn and Sherer [6], Hoang and Rascher [7], Dey [8], Berri et al. [9]), golf (Moy and Liaw [10]), North American hockey (Richardson [11]), and professional futbol in Europe (Szymanski [12], Lucifora and Simmons [13], Dietl et al., [14]).

The literature on American professional football has seen considerable growth in recent years. As with baseball, early research on labor issues in American football dealt primarily with issues of discrimination (Kahn [15], Guis and Johnson [16]). More recent research has tended to focus on the impact of the National Football League (NFL) salary cap and collective 
bargaining on team operation and player compensation (Treme and Allen [17]). In place since 1994, the NFL salary cap sets a team's maximum payroll spending to a fraction of the League's defined gross revenues averaged over its 32 franchises. Indeed, the NFL "hard" salary cap-an individual team's player payroll is not allowed to exceed the salary cap for a given year-raises a number of unique, interesting labor market issues. In particular, the presence of a salary cap may be obscuring the relationship between salary and performance. Indeed, the amount of publicity given to "salary cap casualties," players released because their team deems their salaries excessive as opposed to a noteworthy decline in skills, in sports media makes the issue of football player salaries and performance noteworthy in and of itself.

Another is the nature of the game itself. The incidence of serious injury is considerably higher among NFL players relative to other professional athletes, and NFL careers are accordingly shorter. It is almost by definition more difficult for a player to build a suitable record to determine and predict salaries. Not surprisingly, the incidence of bust (highly overpaid relative to performance) players seems much higher in the NFL than in other leagues. As such, it is possible that standard cross-section wage models may not be able to deliver any meaningful results regarding the relationship between player salaries and performance. Finally, and unlike sports such as baseball and basketball where individual performance is fairly easy to isolate and measure, the standard performance statistics for a professional football player may not accurately depict his value. Indeed, one football position group-offensive line-does not even have a widely established and/or reported uniformly accepted performance metric.

This paper investigates these issues by estimating a fixed-effect log wage model using a panel of veteran NFL offensive skill players for the 2012-2015 seasons. Separate models are estimated for offensive skill players in addition to models based on individual position groups. The results of this analysis suggest support for the above two propositions. Regarding the salary cap, the results show that changing teams has a significantly negative impact on player salaries. Additionally, individual, position-specific skills are not as important, statistically speaking, as durability and experience in determining professional football players' salaries.

\section{Summary Statistics}

\section{THE SALARY STRUCTURE IN THE NFL}

In 2015-the final year of data used in this study - the average salary (base salary plus bonus) for an NFL player was slightly less than $\$ 2$ million. Parsed by position group in Table 1 , one notes that quarterbacks are not surprisingly the highest paid position in the NFL, commanding an average salary of almost \$5 million, over twice that of any other position group. Running backs are the lowest paid players, with an average salary of around $\$ 1.2$ million. Within position groups, there is considerable variation in salaries, as the highest paid players usually earn five to eight times the group average. Indeed, with the exception of placekickers and punters, salary variability exceeds the position group mean. Finally, the income distribution of salaries is generally similar across position groups, at least for the highest paid players. Excluding again placekickers and punters, the 5\% concentration ratio (the share of the position group's combined earnings accounted for by the players at or above the 95th percentile of the salary distribution) for each position group averages just over $27 \%$, while the $10 \%$ concentration ratio is over $43 \%$. 
Table 1: Summary Statistics for NFL Salaries, 2015 season

\begin{tabular}{|c|c|c|c|c|c|c|c|c|c|}
\hline \multirow[b]{2}{*}{ Position Group } & \multirow[b]{2}{*}{$N$} & \multirow[b]{2}{*}{$\begin{array}{l}\text { Avg. } \\
\text { (ths.) }\end{array}$} & \multirow[b]{2}{*}{$\begin{array}{r}\text { St. Dev. } \\
\text { (ths.) }\end{array}$} & \multirow[b]{2}{*}{$\begin{array}{r}\text { Top } \\
5 \% \\
\end{array}$} & \multirow[b]{2}{*}{$\begin{array}{r}\text { Top } \\
10 \% \\
\end{array}$} & \multicolumn{2}{|c|}{ Skewness } & \multicolumn{2}{|c|}{ Kurtosis } \\
\hline & & & & & & $\begin{array}{l}\text { Raw } \\
\text { Data }\end{array}$ & Logs & $\begin{array}{l}\text { Raw } \\
\text { Data }\end{array}$ & Logs \\
\hline Quarterback & 87 & $\$ 4,702$ & $\$ 6,139$ & $20.2 \%$ & $40.9 \%$ & 1.52 & 0.34 & 1.05 & -1.17 \\
\hline Running Back & 173 & $\$ 1,243$ & $\$ 1,919$ & $34.0 \%$ & $46.3 \%$ & 4.11 & 0.01 & 21.29 & 0.80 \\
\hline Wide Receiver, Tight End & 376 & $\$ 1,709$ & $\$ 2,555$ & $30.4 \%$ & $47.3 \%$ & 3.07 & 0.28 & 12.50 & -0.81 \\
\hline Offensive Line & 341 & $\$ 1,965$ & $\$ 2,508$ & $24.5 \%$ & $42.0 \%$ & 2.03 & 0.16 & 3.73 & -1.10 \\
\hline Defensive Line & 296 & $\$ 2,056$ & $\$ 2,877$ & $28.3 \%$ & $43.9 \%$ & 3.06 & 0.30 & 12.28 & -0.67 \\
\hline Linebacker & 311 & $\$ 1,877$ & $\$ 2,409$ & $24.7 \%$ & $40.8 \%$ & 2.30 & 0.13 & 6.79 & -1.14 \\
\hline Defensive Back & 392 & $\$ 1,777$ & $\$ 2,519$ & $29.0 \%$ & $46.0 \%$ & 2.61 & 0.43 & 7.63 & -0.74 \\
\hline Kicker, Punter & 69 & $\$ 1,574$ & $\$ 1,205$ & $11.3 \%$ & $24.5 \%$ & 0.64 & -0.01 & -0.91 & -1.52 \\
\hline
\end{tabular}

Raw salary data tends to be positively skewed for most position groups, concerning what most professional football players already know: for most position groups, there are a handful of elite performers command compensation packages well in excess of group averages. The fact that the NFL also has a salary floor for veteran players - the "veteran minimum"-is also playing a role here. Skewness issues, however, are greatly mitigated with a simple natural logarithm transformation. Most position groups likewise exhibit a high degree of kurtosis, quarterbacks and kickers being noteworthy outliers. Like skewness, however, the degree of kurtosis in my salary data considerably diminished by taking natural logarithms.

Like virtually all professional athletes' compensation, NFL salaries have risen considerably in recent years. Over the four season period ending in 2000, the average NFL salary had risen by some $10 \%$. And by the end of this period, approximately $28 \%$ of all NFL players commanded salaries in excess of $\$ 2$ million annually.

\section{$X$ 's and O's of the Salary Cap}

The NFL salary cap was instituted in 1994 as part of the Collective Bargaining Agreement (CBA) between the NFL owners and the NFL Players Association. In principle, the salary cap is fairly simple: it sets a maximum player payroll for each of the 32 NFL franchises. Moreover, the salary cap sets no stipulations on the salary of individual players; it only sets a limit on the total amount that each team can spend on its combined player salaries. The current incarnation of the NFL salary cap dates to the 2011 CBA ratified after an uncapped season in 2010. The current salary cap includes an overall cap on team player payrolls and a set wage scale and uniform four-year contract duration (with a fifth year team extension option) for rookies based mainly on that player's draft round and selection number.

The present salary cap is uniform for each team and is based upon a share of the League's defined total revenues-all earnings by all NFL teams and the league itself through ticket sales, broadcasting contracts, merchandising, stadium concessions, parking, etc. - divided equally by the number of league franchises. Under the current NFL Collective Bargaining Agreement, the percentage of defined total revenue that can be used for player salaries was $48 \%$ for the 2012 2014 seasons and $48.5 \%$ in 2015 . For the 2015 NFL season, this translates into a player payroll in the neighborhood of $\$ 143$ million per team.

Operating an NFL franchise under the constraint of a player salary cap gets very complicated very quickly. The trade-off that teams face is a very easy to see, but equally difficult to manage: given that better teams tend to have more above-average players, and that better players typically command higher salaries, franchises attempting to maximize team success have a strong incentive to hire relatively more highly-paid players. This, however, obviously increases the likelihood that a team will run up against the constraint of the salary cap well before it is 
fully staffed. Not surprisingly, working around the salary cap, at least in the short term, has become a cottage industry in the NFL, so much so that many franchises have hired "capologists," experts on the accounting and legal aspects of salary cap, to assist with payroll decisions and management (Rovell [18]).

Signing bonuses are one such opportunity for creative cap management. In the case of signing bonuses, the salary cap does not place a strict ceiling on a franchise's player payroll; indeed, every NFL club routinely spends more on player salaries than is dictated by the cap. In particular, players' signing bonuses are paid in full immediately, but can be prorated under the Collective Bargaining Agreement over the life of the contract, yet only the prorated amount is charged under the current year's cap. Another common cap management technique is to renegotiate players' salaries downward to enable teams to stay under the cap; as long as a contract is renegotiated in the proper time frame, and the player in question is still paid at or above the league minimum, franchises can lower player's salaries to stay under the cap. A related, short-term cap practice is to backload contracts so as to be able to initially sign highpaid players, but to avoid making large salary payouts until the final years of the contract. This allows a team to manage other salaries around larger contracts, to potentially renegotiate a contract down at a future date, or in the extreme to release a player before the team has to make its largest salary payments (Lackner [19]). (Guaranteed contracts are extremely rare in the NFL; only signing bonuses are guaranteed.)

\section{The Salary Cap and Veteran Salaries}

NFL experts argue that the salary cap has profoundly changed the relationship between player performance and compensation. One noteworthy impact of the NFL salary cap, or better it most recent incarnation under the 2011 Collective Bargaining Agreement, has been to essentially segment the NFL labor market into one for rookie players and another market for veterans (Allen [20]). In the case of rookie players, compensation is first and foremost a function of when a given player is selected position in the annual college player draft, with a premium placed on first and second round draft picks (Keefer [21]). Regarding veteran players, while as noted a given veteran player's contract may reflect his skills and past performance, his salary for a given year may not; it may be prorated and back loaded. Likewise, contract renegotiating for this purpose could result in a player taking a pay cut that was not warranted by his performance, and even the best players risk release/unemployment if they are deemed highly paid.

This latter possibility, release, gets considerable attention from the sporting media, particularly around the two NFL player release periods in February and June. It is a wellknown fact that churn in the NFL players' labor market has increased tremendously since the introduction of the free agency system in 1992 and the salary cap in 1994. Over the past ten years for example, turnover in the NFL has averaged around $30 \%$ annually, about $10 \%$ of which consists of veteran players being released from their respective teams for reasons other than retirement. While some of these players are released because of declining productivity, many of these cuts are attributed to the salary cap and/or players' unwillingness to renegotiate their contracts downwards. Most of these players end up resigning with another team, most at a substantially reduced salary.

In theory, it should be possible to empirically separate these effects. If salary cap considerations are playing a role in intra-league churn, changing teams should be a significantly negative determinant of players' salaries, all else equal. In contrast, if veteran players' salaries are determined by standard labor market models of wages based on market 
characteristics, one would expect that players released due to declining skills that are signed to new teams would be paid in a manner commiserate with the a (diminished) set of football skills; changing teams should not impact compensation over time in and of itself, all else being equal. This notion in taken up in greater detail in the proceeding section.

\section{DATA, MODEL, AND RESULTS}

\section{Data}

The data for this paper consist of performance and other statistics for a balanced panel of 179 veteran offensive skill players for the 2012-2015 football seasons. Players were categorized by position group on offense: there were 32 quarterbacks, 44 running backs (tailbacks and fullbacks), and 130 receivers (tight ends and wide receivers). Offensive linemen were excluded because this position group does not have a set of uniform and/or publicized performance statistics save Pro-Bowl appearances, All-Pro listings, and more recently Pro Football Focus rankings and grades, the latter of which tends to be controversial and not uniformly accepted as a measure of performance. Placekickers and punters were excluded as most of these players earn salaries at or slightly above the league veteran minimum; only a handful of elite kickers would be considered well-paid in an NFL sense. All included players were on a non-rookie contract at some point during the 2012-2015 period. That is, the panel includes older players with five or more years of experience as of the 2015 season and younger players who had either renegotiated their rookie contract or became free agents, and thus signed a new contract between 2013-2015. Given that the typical NFL career is less than six years, this limits the number of included players, but in theory allows performance to play a more significant role in determining a player's salary.

Performance data are all available online at si.com, nfl.com, and espn.com. All salary information was found at sportrac.com. Data on experience; position; team changes; games and games started; and performance statistics including yards from scrimmage and scoring broken into passing, rushing, and receiving components. In addition, a handful of performance metrics unique to position group are also complied, including quarterback rating, interceptions, and completion percentage for quarterbacks; rushing attempts for runners; and for receivers, pass catches and targets (the number of passes thrown to a given receiver). All performance statistics can be expressed on a per season or per game basis.

\section{A Fixed-effect Model}

To investigate the issue of wage determination in the NFL, I estimate fixed-effect regression models for offensive skill players jointly and for individual position groups using the data described above. The model is:

$$
\ln \left(S A L A R Y_{i t}\right)=\beta^{\prime} X_{i t}+\alpha_{i}+u_{i t}
$$

where "In" denotes natural logarithm, $S A L A R Y_{i t}$ denotes the salary (base plus bonus) of player $i$ at date $t, X$ is a vector of performance variables and position and participation dummies with associated coefficient vector $\beta, \alpha$ is a player-specific intercept, and $u_{i t}$ an error term.

The model is estimated using the usual technique of estimating the following:

$$
\ln \left(S \widetilde{A L A} R Y_{l t}\right)=\beta^{\prime} \widetilde{X_{l t}}+\widetilde{u_{l t}},
$$

where:

$\ln \left(S \widetilde{A L A R} Y_{l t}\right)=\ln \left(S A L A R Y_{i t}\right)+\overline{\ln \left(S A L A R Y_{l t}\right)}$ 


$$
\begin{aligned}
& \widetilde{X_{l t}}=X_{i t}+\overline{X_{l t}}, \\
& \widetilde{u_{\imath t}}=u_{i t}+\overline{u_{l t}} .
\end{aligned}
$$

In the above expressions, "bars" denote the player specific average for each variable or error term. The transformed is estimated using generalized least squares to obtain a consistent estimate of the covariance matrix for $u$ allowing for heteroskedasticity and serial correlation using the methodology described in Arellano [22]. In each case, the models were estimated using a top-down approach: regressors that were not statistically significant at at least $10 \%$ were excluded.

\section{Results}

The results obtained from the above model for offensive skill players jointly and by position group are located in Tables 2 and 3. Looking first at the results from the combined offensive panel (Table 2), one first observes a dearth of significant performance statistics; only lagged total yards from scrimmage is a significant salary predictor and its 0.0004 coefficient magnitude is essentially meaningless. Other performance-based statistics are insignificant for determining a player's salary (in this model). This, however, could be due to a collinearity issue, namely that the other offensive statistics (touchdowns, completion percentage, etc.) tend to be strongly correlated with yardage. That is, players that gain more yards tend to score more touchdowns, all else being equal. Additionally, one could argue that more so than in other team sports, the success of an individual offensive skill player in football is more dependent on the skills and abilities of his teammates. For example, for a receiver to be successful, the offensive line has block well, the running backs have to be able to run, and the quarterback has to successfully read the defense and accurately throw the ball, and the other receivers must be a threat to the defense. Without these uncertain elements, a high-priced receiver will not produce numbers appropriate to his salary. Finally, this finding is largely consistent with Leeds and Kowalewski [23], who find that only the lower paid players tend reap meaningful salary benefits based on performance. In other words, while it may be the case that the best players are the best paid, quantifying precisely what makes an elite player elite is a challenge in American professional football.

Table 2: Regression Results, Pooled Offensive Skill Players Dependent variable: $\ln (S A L A R Y)$

\begin{tabular}{lrrr}
\multicolumn{1}{c}{ Variable } & \multicolumn{1}{c}{$\begin{array}{c}\boldsymbol{t} \text { - } \\
\text { Coefficient }\end{array}$} & statistic & $p$-value \\
\hline \hline Constant & 11.7765 & 33.000 & 0.000 \\
Yards From Scrimmage, season ago & 0.0004 & 4.394 & 0.000 \\
Starting Quarterback Dummy & 0.5112 & -2.529 & 0.012 \\
Years Experience & 0.6652 & 6.931 & 0.000 \\
(Years Experience) $^{2}$ & -0.0340 & -5.408 & 0.000 \\
Games Started & 0.0006 & 5.586 & 0.000 \\
Games Started, season ago & 0.0007 & 5.173 & 0.000 \\
Team Change Dummy & -0.4037 & -5.347 & 0.000 \\
\hline
\end{tabular}

Within $R^{2}=0.52 ;$ Durbin-Watson $=1.62$

Notes:

1. Empirical technique: fixed-effect regression, Arellano [22] robust errors.

2. Panel size: 179 players over 2012-2015 seasons; 32 quarterbacks, 44 running backs, 103 receivers 
A player's position is also a significant determinant of his salary. Not surprisingly, quarterback is the glamour position empirically as well as on the field, as being a starting quarterback translates into an approximate 51\% salary premium over the baseline offensive skill player (receiver). Longevity and durability have a significantly positive impact on player salaries. Each year of experience, for example, adds over $60 \%$ to a player's salary. No doubt this result is picking up the minimum veteran salary scale specified under NFL Collective Bargaining Agreement. Being a multiyear starter similarly results in a positive, but marginal, increase in a skill player's salary.

Finally, changing a team causes an over- $40 \%$ decrease in a player's salary, on average. It is very possible that this is due to the salary cap and the payroll structure it creates. Namely, this result could be reflecting the possibility that most players who change teams do so because their current team has released them, and have been forced to sign to a new contract with a different team, but at a value much lower relative to previous years. This finding is also indicative of backloaded free agent contracts, which would result in a significant salary decrease at the beginning of a contract, but allows for this to be made up later as the contract matures. The other possibility that this finding may not necessarily be a result of the salary cap as some players could be willing to take a pay cut in order to become a starter or to play on a winning or championship-caliber team. Notwithstanding, this result is consistent with research conducted by Duberstein [24], who finds that unrestricted free agents who changed teams from 1993 to 2001 realized an approximate $10 \%$ pay cut.

The above results are also observed when the model is estimated using smaller panels consisting of individual offensive skill position groups (see Table 3). Experience, durability, and changing teams remain the three most important determinants of a player's salary, while the magnitude of the associated coefficients differs by position group. An extra year of experience, for example, is much more valuable to a veteran running back, who is more likely to have an incentive-laden contract, than to a veteran quarterback. As with the full sample, changing teams typically decreases a veteran player's salary by approximately $35-40 \%$ on average. 
Table 3: Regression Results, Offensive Skill Players by Position Group Dependent variable: $\ln (S A L A R Y)$

\section{A. Quarterbacks}

\begin{tabular}{|c|c|c|c|}
\hline Variable & Coefficient & $\begin{array}{c}t- \\
\text { statistic } \\
\end{array}$ & $\begin{array}{c}p- \\
\text { value } \\
\end{array}$ \\
\hline Constant & 11.8432 & 14.410 & 0.000 \\
\hline Passing Yards per Game, season ago & 0.0033 & 2.143 & 0.036 \\
\hline TD-Interception Ratio, season ago & 0.1724 & -2.651 & 0.010 \\
\hline Years Experience & 0.5382 & 2.920 & 0.005 \\
\hline$(\text { Years Experience })^{2}$ & -0.0190 & -2.064 & 0.044 \\
\hline Games Started & -0.0247 & -1.649 & 0.105 \\
\hline Games Started, season ago & 0.0537 & 2.160 & 0.035 \\
\hline Team Change Dummy & -0.4325 & -2.352 & 0.022 \\
\hline
\end{tabular}

Within $R^{2}=0.51 ;$ Durbin-Watson $=1.77$

\section{B. Fullbacks, running backs}

\begin{tabular}{lrrr}
\multicolumn{1}{c}{ Variable } & Coefficient & statistic & $\begin{array}{c}p \text { value } \\
\text { value }\end{array}$ \\
\hline \hline Constant & 10.7552 & 14.600 & 0.000 \\
Rushing Attempts per Game, season ago & 0.0029 & 2.093 & 0.040 \\
Years Experience & 1.1066 & 4.717 & 0.000 \\
(Years Experience) $^{2}$ & -0.0768 & -4.223 & 0.000 \\
Games Started & 0.0084 & 0.421 & 0.675 \\
Games Started, season ago & -0.0275 & -0.857 & 0.394 \\
Team Change Dummy & -0.3261 & -2.603 & 0.011 \\
\hline
\end{tabular}

Within $R^{2}=0.40 ;$ Durbin-Watson $=1.61$

\section{Receivers}

\begin{tabular}{lrrr} 
& & $t-$ & $p-$ \\
Variable & Coefficient & statistic & value \\
\hline \hline Constant & 11.3008 & 22.030 & 0.000 \\
Receptions, season ago & 0.0073 & 3.475 & 0.001 \\
Years Experience & 0.7602 & 5.673 & 0.000 \\
(Years Experience) $^{2}$ & -0.0398 & -4.771 & 0.000 \\
Games Started & 0.0007 & 7.113 & 0.000 \\
Games Started, season ago & 0.0006 & 4.801 & 0.000 \\
Team Change Dummy & -0.3847 & -4.183 & 0.000 \\
\hline
\end{tabular}

Within $R^{2}=0.53 ;$ Durbin-Watson $=1.72$

Notes:

1. Emprical technique: fixed-effect regression, Arellano (1987) robust errors.

2. Panel size: 179 players over 2012-2015 seasons; 32 quarterbacks, 44 running backs, 103 receivers

Estimating the model by position group also allows for a more careful examination of how position-specific performance metrics impact salaries. Passing yards and the touchdown to interception ratio, for example, are a significant determinant of a quarterback's salary, while rushing attempts is important for running backs and fullbacks, and total receptions is again important for receivers. The interesting thing about this analysis is that these performance statistics tend to be significant only with a one-season lag, suggesting that past performance is more important for salary determination than current incentives, on average. On a more 
ominous note, this could be interpreted as that teams may be effective in getting free agent players to sign contracts with performance incentives that are difficult to meet.

As a final point, readers familiar with this line of research will no doubt note that demographic factors, notably race, are absent from this compensation model. This is done for mainly practical reasons. Specifically, almost all of the running backs and receivers in the panel are Black and almost all of the quarterbacks are white. As such, the inclusion of a standard Black/white dummy variable creates an obvious collinearity problem in the position group regressions. A race dummy variable is likewise almost perfectly collinear with the starting quarterback dummy in the combined panel. Finally, all preliminary, unreported model variants that included a race dummy failed to produce a significant coefficient, a result consistent with Gius and Johnson [16] and Ducking et al. [25], who find no evidence of racial discrimination in the post-1995 NFL.

\section{SUMMARY AND CONCLUSION}

Economists have traditionally viewed professional athletics as an excellent laboratory to examine wage and salary determination. The labor markets for professional athletes tend to be highly competitive, and are characterized by a high degree of labor mobility. In this regard, the NFL is a textbook example of a sports labor market. Similarly, the criteria that are used to evaluate the individual productivity of a professional athlete are reasonably well-established and accepted, and are easy to observe. Thus there should be, at least in theory, a clear and easily quantifiable relationship between an athlete's performance/productivity and his or her salary.

In this regard, the NFL's labor market is arguably unique. In part, the NFL's labor market is unique because of the nature of the game of football. Football is a very violent sport; players that are highly productive one year may not even be on the field the next due to injury. Similarly, NFL careers are very short, making it difficult for an individual player to build consistent performance record. Likewise, football is a highly specialized team sport. The skills requisite for individual success in football differ greatly across position groups. Likewise, individual success is arguably more dependent one's teammates than in other team sports. The NFL's labor market is also unique because its employers are constrained by a salary cap which places a strict, uniform ceiling on each team's player payroll. As such, these factors may destabilize or eliminate any measurable link between a player's current performance and his current compensation.

This paper investigates this issue by estimating a standard log wage model for a four season panel of veteran NFL offensive skill players. The preliminary results of this study that the NFL's labor market is indeed unique. For offensive skill players, both jointly and by position group, I find that the usual performance statistics are of secondary importance in determining players' salaries, and that performance statistics are only significant determinants of player salaries when lagged. In contrast, longevity and durability are more important to the NFL salary structure than measured individual productivity. Moreover, results indicate that players who change teams suffer a significant salary decrease. All else being equal, it appears as if financial considerations alone, that is, fitting under the salary cap, may be resulting in a player's separation from his current team. Further study is no doubt required, but this paper provides some preliminary evidence supporting the widespread claim that the salary cap fundamentally affects the way the NFL does business, and how the NFL's labor market operates. 


\section{ACKNOWLEDGEMENTS}

I would like to thank John Linnehan for valuable research assistance.

\section{References}

Gwartney, J. and C. Haworth, Employer Costs and Discrimination: the Case of Baseball. Journal of Political Economy, 1974. 82(4): p. 873-881.

Medoff, M., On Monopsonistic Exploitation in Professional Baseball. Quarterly Review of Economics and Business, 1976. 16(2): p. 113-121.

McDonald, D. and M. Reynolds, Are Baseball Players Paid Their Marginal Products? Managerial and Decision Economics, 1994. 15: p. 443-457.

Irani, Daraius. (1996). Estimating Customer Discrimination in Baseball Using Panel Data in Baseball Economics: Current Research, J. Fizel, E. Gustafson, and L. Hadley, Editors, Wesport, CT: Praeger, 1994. p. 47-61.

Hanssen, A., The Cost of Discrimination: A Study of Major League Baseball. Southern Economic Journal, 1998. 64(3): p. 603-627.

Kahn, L. and P. Sherer, Racial Differences in Professional Basketball Players Compensation. Journal of Labor Economics, 1988. 6(1): p. 40-61.

Hoang, H. and D. Rascher, The NBA, Exit Discrimination, and Career Earnings. Industrial Relations, 1999. 38(1): p. 69-91.

Dey, M, (1997). Racial Differences in National Basketball Association Players Salaries: Another Look. The American Economist, 1997. 41(2): p. 84-90.

Berri, D., Leeds, M., and P. von Allmen, Salary Determination in the Presence of Fixed Revenues. International Journal of Sport Finance, 2015. 10(1): p. 5-25.

Moy, R. and T. Liaw, Determinants of Professional Golf Tournament Earnings. The American Economist, 1998. 42(1): p. 65-70.

Richardson, D, Pay, Performance, and Competitive Balance in the National Hockey League. Eastern Economic Journal, 2000: 26(4): p. 393-417.

Szymanski, S, A Market Test for Discrimination in the English Professional Soccer Leagues. Journal of Political Economy, 2000. 108(3): p. 590-603.

Lucifora, C. and R. Simmons, Superstar Effects in Sport: Evidence From Italian Soccer. Journal of Sports Economics, 2003. 4(1): p. 35-55.

Dietl, H., Franck, E., Lang, M., and A. Rathke, Salary Cap Regulation in Professional Team Sports. Contemporary Economic Policy, 2012. 30(3): p. 307-319.

Kahn, L., The Effects of Race on Professional Football Players' Compensation. Industrial and Labor Relations Review, 1992. 45(2): p. 295-310.

Gius, M. and D. Johnson, Race and Compensation in Professional Football. Applied Economics Letters, 2000. 7(2): p. 73-75.

Treme, J. and S. Allen, Press Pass: Payoffs to Media Exposure Among National Football League (NFL) Wide Receivers. Journal of Sports Economics, 2011. 12(3): p. 370-390.

Rovell, D., Capologists: Who Are These People? Online at ESPN.com, 2000. http://assets.espn.go.com/nfl/preview00/s/000826capologists.html.

Lackner, A., NFL Salary Cap FAQs. Online at AskTheCommish.com, 2017.

http://www.askthecommish.com/SalaryCap/Faq.aspx.

Allen, W., The Demand for Younger and Older Workers: Patterns from NFL Labor Markets." Journal of Sports Economics, 2015. 16(2): p. 127-158.

Keefer, Q., The 2011 NFL Collective Bargaining Agreement and Drafted Player Compensation. International Journal of Sport Finance, 2016. 11(3): p. 221-231.

Arellano, M., Computing Robust Standard Errors for Within-groups Estimators. Oxford Bulletin of Economics and Statistics, 1987. 49(4): p. 431-434. 
Leeds, M. and S. Kowalewski, Winner Take All in the NFL: the Effect of the Salary Cap and Free Agency on the Composition of Skill Position Players. Journal of Sports Economics, 2001. 2(3): p. 244-256.

Duberstein, M., It Happens Every February: Media Misperceptions of the Current NFL System. Manuscript, NFL Players Association Research Department, 2002.

Ducking, J., Groothuis, P., and J. Hill, Compensation Discrimination in the NFL: an Analysis of Career Earnings. Applied Economics Letters, 2014. 21(10): p. 679-682. 